\title{
LAS TENUES VOCES DEL CLAUSTRO. LAS CARTAS DE PROFESIÓN DEL MONASTERIO DE SAN CLEMENTE EL REAL DE SEVILLA
}

\section{FAINT VOICES OF THE CLOISTER. VOCATION LETTERS AT MONASTERY OF SAN CLEMENTE REAL SEVILLE}

\author{
Rosario Marchena Hidalgo \\ Universidad de Sevilla. España \\ romahi@us.es
}

\begin{abstract}
La vida de las monjas de clausura apenas ha dejado más rastro que el que queda en los libros de registro y en las cartas de profesión. Éstas recogen la ceremonia por la que la novicia se compromete a formar parte de la orden para siempre. En el monasterio de San Clemente se conserva una, muy deteriorada, del siglo XVII, ninguna decorada del XVIII, 33 del XIX y muchas más del XX y XXI. Las cartas del siglo XIX han sufrido una transformación pues se han aprovechado, adaptando el texto, para profesiones posteriores. De 1904 a 1917 hay seis cartas aprovechadas de las nueve que se conservan de este periodo. A partir de este momento las cartas iluminadas se van reduciendo siendo la última de 1941.

Palabras clave: Monasterio de San Clemente, comunidad cisterciense, hábitos, cartas de profesión, iluminación.
\end{abstract}

Cloister nuns' life has barely left tracks behind than those found in Registry Books and Vocation Letters. Letters record the ceremony that novice agrees and becomes engaged for life. Some of them are preserved at Monastery of San Clemente, one damaged from 17th century, none from 18th century, thirty three from 19th century and several more from 20th and 21th centuries. Letters from 19th century have been deeply transformated as they have used, adapting the text, for following vocations. Six of the nine letters found from 1904 to 1917, have been used too. From this period to present, amount of illuminated letters have been progressively decreasing.

Keywords: Monastery of San Clemente, Cistercian Community, habit, Vocation Letters, illumination. 


\section{VIDA CONVENTUAL}

El monasterio de San Clemente de Sevilla, fundado por Fernando III el Santo poco tiempo después de la conquista de la ciudad en 1248, tuvo desde los primeros momentos una relevancia especial, además de por ser fundación real y luego convertirse en panteón, por contar con el apoyo de instituciones como el arzobispado o el gobierno municipal. Ocupado por la orden monástica del cister femenino, desde sus inicios fue elegido por las más altas capas de la sociedad sevillana, incluida la real, para que sus mujeres profesaran en él, tendencia que continuó a lo largo del tiempo aunque se fue abriendo poco a poco al estamento no privilegiado. Las donaciones y las dotes que aportaban las profesas convirtieron al monasterio en un gran propietario cuyas rentas permitían a la comunidad dedicarse íntegramente a cumplir su función religiosa sin tener preocupaciones materiales, al menos en teoría ${ }^{1}$. Su antigüedad, su tradición cultural y sus necesidades lo convirtieron en un compendio de riquezas artísticas, arquitectura, escultura, pintura, orfebrería, miniatura..., y culturales, archivo y biblioteca. Pero junto a esos valores materiales existen otros intangibles formados por la vida de la comunidad basada en la oración a través de la cual llevan la voz de todos los hombres a Dios. Es el aliento de las monjas que han pasado por este monasterio a lo largo de casi sus 800 años de existencia el que se aprecia al estudiar los documentos de su archivo, los libros de su biblioteca y el entorno en el que se mueven.

En San Clemente existió desde su fundación una nutrida comunidad femenina $^{2}$ formada básicamente por las monjas que habían profesado en él. Desde enero de 1690 se conoce el número exacto de ellas a través de las actas de las reuniones que se celebraban cada tres años para elegir los cargos en las que se aprecia una disminución paulatina. En ese momento el número de ellas era de 86, al terminar el siglo XVIII era de 34 y al final del XIX de 20. La comunidad más reducida se da en 1774 con 14 monjas para ir recuperándose levemente en los años siguientes y contar con 19 en 1905, último año que se recoge en estas actas ${ }^{3}$.

Aparte de las monjas, en el convento vivían otras personas. Unas de esas seglares eran las sirvientas en número que, a veces, superaba el de las mismas monjas. En un documento de 1770, junto a las 46 monjas había 39 sirvientes de "adentro" y 7 sirvientes de "afuera"4. Pero además el monasterio acogía a

${ }^{1}$ BORRERO FERNÁNDEZ, Mercedes: "El Real Monasterio de San Clemente. Expresión del monacato femenino sevillano" en Real Monasterio de San Clemente: historia, tradición y liturgia. Córdoba, 1999, pp. 27-76.

2 FERNÁNDEZ GÓMEZ, Fernando: "San Clemente, una fundación del cister en Sevilla. Vida espiritual y conventual" en Real Monasterio de San Clemente, op. cit., pp. 77-194.

${ }^{3}$ AMSC. (Archivo del Monasterio de San Clemente). Vida conventual, legajo 85, n 12 , pp. 93-141.

${ }^{4}$ AMSC. Vida conventual, Leg. 86, nº 89. 
hermanas y madres de monjas, educandas y viudas. El Libro de seglares difuntas en el Real Monasterio de San Clemente de Sevilla recoge la defunción, el 8 de diciembre de 1864 de la señorita, que estaba en clase de educanda, Elisa Ángela María de la Caridad, hija de Lorenzo Velázquez y de Ángela Ponce de León ${ }^{5}$ y por lo tanto hermana de la profesa sor Angela Velázquez Gaztelu y Ponce de León que también entró en el monasterio de educanda con 12 años ${ }^{6}$. No es el único caso pues el 18 de enero de 1752 muere en el convento la seglar Micaela de Vargas Machuca, perteneciente a una familia presente en el monasterio desde más de 100 años atrás. De la misma manera son abundantes las solicitudes de muchas viudas para residir por un tiempo en el monasterio.

De todos los documentos que nos aportan información sobre la vida de las profesas los más importantes son los libros de hábitos y profesiones, que era obligatorio llevar desde mediados del siglo XVI. Están formados por una serie de actas en las que se recogen todos los datos de la monja: nombre, edad y lugar de nacimiento, nombres de sus padres, cargos y títulos, y, en ocasiones, la dote que aportan al ingresar en el monasterio. En el monasterio de San Clemente existen cinco libros de hábitos y profesiones que abarcan desde 25 de noviembre de 1614 hasta nuestros dias ${ }^{7}$ en donde está mil veces repetido el proceso seguido para tomar el hábito, es decir para que una seglar se convirtiera en novicia lo que estaba perfectamente regulado desde el siglo XVI en el rico y pequeño librito impreso Ordinario para dar ábitos a las doncellas ${ }^{8}$.

La aspirante, con ropa seglar, diciendo que quería tomar el hábito para vivir en religión, se presentaba ante el examinador que la recibía en la sacristía del convento y le tomaba juramento. Ella, prometiendo decir la verdad, iba respondiendo a las preguntas acostumbradas. La primera de ellas era su nombre y el de sus padres. En el monasterio de San Clemente profesaron desde su fundación las mujeres de la alta sociedad sevillana según se desprende de sus apellidos, Fernández de Córdoba, de los títulos nobiliarios de sus padres, Marqueses de Grañina y el hidalgo Arias Pardo de Cela, o de los cargos que ostentan en la ciudad, como

5 AMSC. Vida conventual, Leg. 87, $\mathrm{n}^{\circ} 123$ bis, s/f.

${ }^{6}$ AMSC. Vida conventual, Leg. 85, $\mathrm{n}^{\circ} 12$, ff. $31 \mathrm{v}-32 \mathrm{r}$.

7 AMSC. Vida conventual, Leg. 85, $\mathrm{n}^{\circ}$ 15, Libro de abitos y de las profesiones del Monasterio de San Clemente el Real; Leg. 85, n 17, Avitos y Professiones del Monasterio del Señor San Clemente El Real de Sevilla. Desde Veinte y siete de Agosto de 1637-1659; Leg. $85, \mathrm{n}^{\circ} 18$, Libro donde se asientan los velos y professiones, que se hacen, y dan, en el Real Convento de San Clemente de Sevilla que es de Monjas de la Orden de San Bernardo. Comiença desde $1^{\circ}$ de henero de 1659; Leg. 86, $\mathrm{n}^{\circ}$ 46, Libro de Abitos y professiones deste convento de San Clemente el Real. Año de 1717 y Libro de Ábitos y profesiones De este Monasterio Real de San Clemente. Año de 1788,(sin catalogar).

${ }^{8}$ ORTIZ DE MATIENZO, Sancho: Ordinario para dar ábito a las doncellas que quisieren ser monjas en el Real Monasterio de San clemente de Sevilla, s/f, s/l. Biblioteca del monasterio A-1017 y A-1027. 
los caballeros Veinticuatro de Sevilla, Gaspar de Vargas Machuca y Andrés de Erbas. También aparecen otras personas distinguidas en la sociedad sevillana como los capitanes Juan de Lumbreras Ortiz y Diego de Arias Maldonado. Ya en el siglo XIX se van sumando nombres que representan a la burguesía urbana mercantil e industrial. Asegura la aspirante ser hija legítima y en la mayoría de los casos eso es así pero son conocidos los de las hijas naturales que buscan refugio en el convento probablemente para expiar los pecados de los padres. Quizás el ejemplo de más alcurnia sea la profesión, en torno a 1628, de sor Ana Dorotea de Austria, hija del Emperador Rodolfo II, en el monasterio de las Descalzas Reales de Madrid ${ }^{9}$. Más próximo y enternecedor es el caso de la niña de 6 o 7 años María de Carvajal que dice que no sabe quién es su madre y a la que su padre, García Díaz de Ortega, interna en el monasterio de San Clemente, junto a su medio hermana Juana María de Carvajal, novicia desde 1621, con toda probabilidad, para darle el mejor futuro posible y ocultarla a los ojos del mundo ${ }^{10}$.

También la edad queda reflejada en estos documentos pues forma parte de esa primera pregunta que le hacen los examinadores a las aspirantes. La mayoría se mueven entre los 20 y los 35 años pero son muy abundantes las que tenían 14 años como Gerónima de Meza, el 5 de junio de 1615, Bernardina de Neira Puerto Carrero, el 13 de enero de 1619, Bernarda María Ramírez, el 13 de junio de $1637^{11}$, Isabel Ana Niño de Velasco, el 6 de enero de $1667^{12}$ o Gabriela Juliana Abet, el 20 de mayo de $1717^{13}$. También habían niñas de 13 años como Isabel de Porras, y de doce como Ana María de Vargas Machuca, el 25 de noviembre de 1614, Juana Puerto Carrero, el 13 de enero de 1619, Juana María de Carvajal y Clara de Gámez ${ }^{14}$. Probablemente las edades más bajas para tomar el hábito sean los 9 años y cuatro meses que tenía el 2 de agosto de 1626 Gerónima de Algarín y los 6 ó 7 de la citada María de Carvajal. Muy por encima de estas edades están los 59 años que tenía al tomar el hábito Feliciana Bretaña y Muñoz el 10 de mayo de 1885 y los 62 de Teresa Domínguez y Martín el 29 de enero de $1888^{15}$. La media de edad en el siglo XIX es de 25,19 años obtenida de las 94 actas de toma de hábito de este siglo.

A la segunda pregunta del examinador responde la aspirante que ha solicitado la toma de hábito libremente. Pese a que afirme que no busca en el convento un puerto seguro donde esconderse del mundo, lo que la inducía a encerrarse allí

9 DE LA MORERA BARTOLOMÉ, Aúrea: Catálogo clausuras. Tesoros artísticos en los conventos y monasterios madrileños. Madrid, 2007, p. 9.

${ }^{10}$ AMSC. Vida conventual, Leg. 85, $\mathrm{n}^{\circ} 15$, s/f.

${ }^{11}$ AMSC. Vida conventual, Leg. 85, $\mathrm{n}^{\mathrm{o}}$ 15, s/f.

${ }_{12}$ AMSC. Vida conventual, Leg. 85, $\mathrm{n}^{\mathrm{o}} 17$, s/f.

13 AMSC. Vida conventual, Leg. 85, $\mathrm{n}^{\circ} 18$, ff. 22 v. y 235 v.

${ }_{14}$ AMSC. Vida conventual, Leg. 85, $\mathrm{n}^{\circ} \mathrm{15}$, s/f.

15 AMSC. Vida conventual, Libro de Ábitos...de 1788 (sin catalogar), pp. 267 y 277. 
no siempre era el fervor religioso pues éste se convirtió, con alguna frecuencia, en refugio de huérfanas, viudas y muchachas a las que no se había podido arreglar un matrimonio conveniente por lo que no tenían sitio en el siglo. El convento fue, además, el mejor destino posible para algunas niñas que allí recibieron una educación. Este es el caso de Ysidora Bermúdez que se había criado en el convento desde los 9 años. Allí aprendió música y a tañer el órgano y, muertas las religiosas que lo hacían, la abadesa, Leonor de Guía, y el resto de las monjas solicitaron para ella el hábito y el 3 de diciembre de 1659 el velo ${ }^{16}$. No es este el único caso, pues niñas de 6 a 12 años, cuya toma de hábito está contrastada, solo podían buscar en el monasterio un colegio interno a la usanza del momento. En la mayoría de los casos, aunque existan otros motivos como el social, el económico y hasta el político, es verdadera vocación por la vida religiosa lo que lleva a estas mujeres tras los muros del convento aunque ciertos documentos alerten sobre la presión de la familia para encerrar a algunas aspirantes en el monasterio. El caso más notorio, porque ha dejado un rastro documental entre 1546 y 1548, es el de la monja profesa Francisca de Rivera a la que Roma concedió licencia para abandonar la vida religiosa lo que no estaban dispuestos a consentir ni su madre ni el monasterio ${ }^{17}$. En cualquier caso las monjas que querían abandonar la vida conventual aparecen reflejadas en el Libro de las religiosas que renuncian o hacen contrarrenuncia ${ }^{18}$.

Es difícil determinar cuál fue la causa que llevó al convento a muchas hermanas, si fue un clima especialmente religioso vivido en el domicilio familiar o si fue una estrategia para colocar en sitio seguro a los miembros femeninos de la familia. Ilustra muy bien esta circunstancia el caso de cuatro hermanas, María, Manuela, Isabel Ana y Catalina Niño de Velasco que no solo ingresan en San Clemente juntas sino que hacen coincidir las fechas de las ceremonias: el 21 de septiembre de 1665 toman el hábito María, de 18 años, y Manuela, de 15 ; el 6 de enero de 1667 toma el hábito Isabel Ana, de 14 años, y profesan María y Manuela; el 5 de junio de 1673 toma el hábito Catalina, de 19 años, y profesa Isabel Ana y, por último, el 17 de junio de 1674 profesa Catalina ${ }^{19}$. Sin llegar a tantas mujeres de la misma familia Ana María de Vargas Machuca y Flores toma el hábito el 13 de enero de 1614, el mismo día en que su hermana Leonor de Guía de Vargas Machuca profesa y Juana Puerto Carrero y su hermana Bernardina de Neira Puerto Carrero toman el hábito juntas el 13 de enero de 1619.

\footnotetext{
${ }_{16}$ AMSC. Vida conventual, Leg. 85, $n^{\circ} 17$, s/f.

17 BORRERO FERNÁNDEZ, Mercedes: Inventario General del Archivo del Real Monasterio de San Clemente de Sevilla. Sevilla, 1996, pp. 127-128.

${ }_{18}$ AMSC. Vida conventual, Leg. 86, $\mathrm{n}^{\circ} 78$.

19 AMSC. Vida conventual, Leg. 85, n 18, folios 17 r., 18 r., 22 v., 23 v., 24 v., 76 v., 75 v. y $83 \mathrm{v}$.
} 
Por último, para finalizar el examen a que habían sido sometidas, las aspirantes aseguran no estar casadas ni haber dado palabra de matrimonio, no tener deudas en el siglo que pagar por justicia, no tener enfermedad oculta ni contagiosa y firman, si saben hacerlo, su declaración.

Al año de la toma de hábito la novicia hace la profesión solemne. Es sometida al mismo interrogatorio de la toma de hábito con pequeñas diferencias. Acude a la entrevista vestida de novicia y declara que ha cumplido el año de noviciado, en cuyo tiempo ha experimentado las cargas y obligaciones que tienen las religiosas, que sabe que tienen Regla y Constituciones que guardar y que cuando profesan hacen los votos de Obediencia, Pobreza, Castidad y Perpetua Clausura. Esta profesión puede ser como religiosa de coro y velo negro o como lega u organista, categorías muy bien diferenciadas por su formación, su función y sus obligaciones. Las de velo negro llevan una vida contemplativa dedicadas a la oración, al rezo del Oficio Divino y son las que, procedentes de las familias más pudientes y habiendo entregado en el monasterio una buena dote, van a ocupar los escalones más altos de su dirección y administración. Las legas, por el contrario, que son las religiosas de velo blanco, se ocupan de las tareas domésticas y no están obligadas a acudir a los Oficios Divinos, sino únicamente a la misa diaria y a Completas. La rígida estratificación socio-económica del siglo se reproduce dentro de los muros del convento. Las actas de hábito y profesión recogen la situación de estas hermanas legas e incluso sus obligaciones. En mayo de 1823, frente a las 29 profesas del monasterio, no había ninguna lega ${ }^{20}$ pero el 3 de septiembre de 1824 sor María Josefa de la Santísima Trinidad Ximénez "profesó como religiosa lega y de vida activa con la obligación de asistir a las enfermas" ${ }^{21}$. La distinta consideración que tenían las monjas de velo negro y las legas se manifiesta incluso a la hora de la muerte. El Libro de las religiosas difuntas del Real Monasterio de San Clemente de Sevilla hace un resumen de sus cargos, su actividad y una valoración de su vida en el convento especificando el... "entierro y demás exequias que han correspondido a su grado de religión" 22 .

Aunque lo habitual fuera profesar tras un año de noviciado, hubo excepciones notables, unas por reducir el tiempo entre las dos ceremonias a unos pocos días, caso de Manuela Melgares y Pereira cuya toma de hábito fue el 28 de abril de 1902 y la profesión el 1 de mayo del mismo año ${ }^{23}$, quizás porque ya había tomado el hábito por primera vez en 1896. El otro caso, el de espaciar mucho las

${ }^{20}$ AMSC. Vida conventual, Leg. 86, $\mathrm{n}^{\circ}$ 12, Estado que manifiesta el número de conventos de Religiosas que hay en la Ciudad de Sevilla con expresión de Instituto, número de religiosas Profesas y Legas en mayo de 1823.

${ }^{21}$ AMSC. Vida conventual, Libro de Ábitos...Año de 1788, f. 91 r.

${ }^{22}$ AMSC. Vida conventual, Leg. $85, \mathrm{n}^{\circ} 12$.

${ }^{23}$ AMSC. Vida conventual, Libro de Ábitos...de 1788, p. 294 (a partir de la página 206 está paginado). 
dos ceremonias, está muy bien representada por Ana María Jiménez Velázquez que profesó el 18 de marzo de 1852 después de 17 años o por María de los Dolores Elizaga Tres Sierras que tomó el hábito el 11 de julio de 1835 y profesó el 13 de febrero de $1852^{24}$. La separación entre la fecha de toma de hábito y la de profesión puede deberse a la corta edad con que se entra en el convento. Este parece ser el caso de Ana María Vargas Machuca que profesó el 6 de julio de 1621 casi siete años después de haber tomado el hábito con 12 años ${ }^{25}$. Las edades que aparecen en las actas son prácticamente las mismas que para la toma de hábito y de igual modo hay algunas muy por debajo de las centrales como los 16 años que tenían Bárbara Carrión Flores el 9 de febrero de 1806, Josefa Ballester Pinto el 20 de julio del mismo año y María Gertrudis Navamuel Ramos, el 27 de diciembre de 1807 y otras muy por encima como los 60 años de Feliciana Bretaña Muñoz el 16 de mayo de 1886 o los 63 de Teresa Domínguez Martín, el 14 de febrero de $1889^{26}$. La media de edad de las profesiones, extraída de las 61 actas del siglo XIX es de 24,27 años.

El ingreso en el convento, tras la toma de hábito, había supuesto un giro radical para la novicia pues al iniciar su vida religiosa había cambiado su identidad al elegir otro nombre. Con la ceremonia de la profesión la monja moría definitivamente para el mundo. Muy aclaratorias son las siguientes palabras: "Por la profesión religiosa te ofreces y sacrificas a Dios. Haces una solemne abnegación de ti misma, te consagras a la obediencia. Para ti ya no hay padres, hermanos, parientes ni amigos. En una palabra, ya no hay mundo para la que ha entrado en Religión. Las lúgubres paredes del claustro son para la Religiosa todo el ámbito de la tierra" ${ }^{27}$. Efectivamente así era pues no salían del convento ni muertas porque eran enterradas en sus propias iglesias, claustros y huertos.

Las mujeres, salvo casos muy puntuales, han sido tradicionalmente relegadas de la vida pública, olvidadas y silenciadas, pero las monjas de clausura han llegado a un estadio superior al convertirse en invisibles para la historia. Su vida tras los muros del convento apenas ha dejado más rastro que el que queda en los libros de registro, y en las cartas de profesión. Algunas de las monjas no se resignaron a esta invisibilidad recurriendo al único medio a su alcance para salir de ella: la escritura. Sor Juana Inés de la Cruz, profesa del convento de San Jerónimo de México, tras la inscripción de su profesión, que termina con Dios me haga santa, añade, haciendo evidente su deseo de salir del olvido: "Aquí arriba se

\footnotetext{
${ }^{24}$ AMSC. Vida conventual, Libro de Ábitos...de 1788, ff. 171 r. y 164 r.

${ }^{25}$ AMSC. Vida conventual, Leg. 85, $\mathrm{n}^{\circ} 15$, s/f.

${ }^{26}$ AMSC. Vida conventual, Libro de Ábitos...de 1788, folios 64 r., 69 r. y 72 v. y pp. 276 y 280.

${ }^{27}$ MANEGAT, José Antonio: Cartas críticas del abate Matanegui por las que se conocen los errores que cometen los hombres con más frecuencia. Madrid, Imprenta Real, 1793, p. 90.
} 
ha de anotar el día de mi muerte, mes y año, suplico por amor de Dios y de su purísima Madre a mis amadas hermanas las religiosas que son y en adelante lo fueren me encomienden a Dios que he sido y soy la peor que ha habido. A todos pido perdón por el amor de Dios y de su Madre. Yo la peor del mundo"28.

El nivel cultural de estas monjas se ha intentado deducir del hecho de que firmen las actas y las cartas de profesión pero esa circunstancia no es determinante. Ana María de Vargas no firma su acta de toma de hábito por no saber escribir pero cuando profesa, el 6 de julio de 1621, sí firma y dice que ha sido enseñada en los años, casi siete, de noviciado. También afirman no saber escribir Juana Puerto Carrero, de doce años de edad, el 13 de enero de 1619, e Ysabel de Porras, de $13,{ }^{29}$. Todo parece indicar que estas niñas fueron enviadas al monasterio para ser instruidas.

\section{CARTAS DE PROFESIÓN}

Las cartas de profesión son los documentos en los que se refleja la ceremonia por la cual la monja que va a profesar se compromete formalmente y ante testigos a formar parte de la orden para siempre. Algunas de ellas han salido a la luz en estudios sobre el monacato femenino pero su análisis como objetivo principal es reciente y va apareciendo en trabajos muy dispares por su profundidad, extensión y enfoque ${ }^{30}$. La fórmula es prácticamente igual a lo largo del tiempo.

${ }^{28}$ SCHMIDHUBER DE LA MORA, Guillermo: "El libro de Profesiones del Convento de San Jerónimo de México: la profesión de Sor Juana Inés de la Cruz”, eHumanista, volumen 19, 2011, pp. 538-547.

${ }^{29}$ AMSC. Vida conventual, Leg. 85, ${ }^{\circ}$ 15, s/f.

${ }^{30}$ FERNÁNDEZ GÓMEZ, Fernando: "San Clemente. Una fundación del Cister en Sevilla. Vida espiritual y conventual" en Real Monasterio de San Clemente: historia, tradición y liturgia. Córdoba, 1999, pp. 77-194. CAMACHO MARTÍNEZ, Rosario "Las cartas de profesión del convento del Cister de Málaga: un documento sobre la devoción, el derecho y el arte" en Actas del Simposium "La Clausura femenina en España". San Lorenzo de El Escorial 2004, pp. 717.740. MARCHANT RIVERA, Alicia: "Aproximación a la diplomática eclesiástica a través de la documentación conventual: las cartas de profesión de la abadía cisterciense de Santa Ana de Málaga" en Diplomática antigua. Diplomática moderna. III Jornadas de la Sociedad Española de Ciencias y Técnicas Historiográficas. Murcia, 2005, pp. 319-331. PASTOR TORRES, Álvaro: "Iconografía e iconología de la Inmaculada en el monasterio sevillano de Santa Paula" en Actas del Simposium "La inmaculada Concepción en España”. San Lorenzo de El Escorial, 2005, Vol. II, pp. 935-964. MARCHANT RIVERO, Alicia: Religiosas del cister malagueño. Catálogo de las cartas de profesión de la Abadía de Santa Ana. Madrid, 2010. RUIZ BARRERA, María Teresa: "Devoción y arte conjugados en las cartas de profesión del monasterio mercedario de San Andrés de Marchena (Sevilla)" en Actas del Simposium "La Clausura femenina en el mundo hispánico: una fidelidad secular”. San Lorenzo de El Escorial, 2011, Vol. II, pp. 985-1002. 
"Yo....prometo mi permanencia y estabilidad, reforma de mis costumbres, Pobreza, Castidad y Obediencia conforme a la regla establecida por nuestro Santo Padre el Señor San Benito Abad, delante de Dios y de sus Santos, cuyas reliquias existen en este Monasterio, llamado San Clemente de la Orden del Cister, en honor de la Bienaventurada Virgen María, y de los Bienaventurados Confesores nuestros Padres Señor San Benito y Señor San Bernardo en presencia del Señor...(oficiante) por el Señor... Arzobispo de Sevilla y de la Señora Doña... Abadesa de este Real Monas-

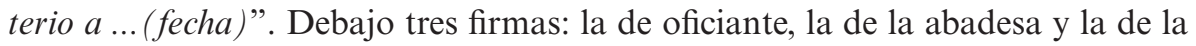
profesa.

La fecha de estas cartas coincide generalmente con la que aparece en las actas de profesión. El idioma usado suele ser el latín hasta 1963 y el castellano a partir de ese momento.

El material de estos documentos es el papel, el más abundante, sobre todo en el siglo XX, el cartón, del que hay cinco del XIX, el pergamino y el cartón fotográfico del que no aparece más que un caso. De cartón es el documento de profesión de sor Eloísa de Santa Teresa (4-II-1882), en el siglo Eloísa Alonso Pérez, que tomó el hábito el 9 de enero de 1881 y profesó un año después ${ }^{31}$. El texto ocupa un óvalo coronado por el escudo real y enmarcado por una palma dorada y una rama de azucenas (Figura 1). Fuera de él están las tres firmas, del oficiante, el obispo Marcelino Spínola Maestre, de la abadesa, María del Patrocinio Caro Ganzinotto, y de la profesa. De pergamino es la carta de sor María del Santo Patriarca José (12-IX-1802), en el siglo María de la Candelaria Molner Pérez, que tomó el hábito con 20 años el 10 de septiembre de 1801 y profesó un año después $^{32}$. El texto en la parte de abajo, está enmarcado por una guirnalda de rosas lo mismo que los tres círculos que deberían haber acogido las firmas inexistentes. La iluminación representa misterios de la fe, la Inmaculada y la Trinidad, los santos de la orden, san Benito y san Bernardo, del monasterio, san Clemente y san Fernando, del santo patrón de la profesa, san José, y otros santos muy representados en las cartas de profesión, santa Gertrudis la Magna y san Luis Gonzaga. Completa la información que nos aportan todos estos elementos un paisaje de Sevilla con la Giralda (Figura 2). De cartón fotográfico, usado para hacer litografías y pegar fotos, es la carta de sor María Dolores de San Luis y San José (15-II-1852), en el siglo María Dolores Elizaga Tressierras, que tomó el hábito el 11 de junio de 1835 , con 15 años, profesó el 13 de febrero de $1852^{33}$, fue nombrada enfermera

PÉREZ DE TENA, Ana: "Cartas de profesiones de fe del convento de Santa María la Real de Bormujos (Sevilla)" en Cuadernos de los Amigos de los Museos de Osuna, 15, 2013, pp. 44-48.

31 AMSC. Vida conventual, Libro de Ábitos...de 1788, pp. 247 y 250.

32 AMSC. Vida conventual, Libro de Ábitos... de 1788, folios 39 r. y 49 r.

33 AMSC. Vida conventual, Libro de Ábitos... de 1788, folios 165 r. y 167 v. 
en $1855^{34}$ muriendo el 11 de enero de $1882^{35}$. El texto está inscrito en un óvalo de cintas y hojas, dejando fuera de él las firmas del oficiante, el presbítero Juan Nepomuceno Escudero, de la abadesa, Raimunda Ariza, y de la profesa. Las ilustraciones son un ejemplo de información complementaria al texto: santos del Cister, del monasterio y la Virgen de los Dolores, san José y san Luis Gonzaga aludiendo al nombre de la monja.

Los tamaños de los documentos del siglo XIX oscilan entre los 420 x $320 \mathrm{~mm}$. y los 650 x $552 \mathrm{~mm}$. siendo la media 517 x 394. Las cartas de la primera mitad del XX mantienen estas medidas pero las de la segunda y las del siglo XXI no superan el tamaño cuartilla. No es frecuente que tengan un formato apaisado pero existe alguna carta del XIX así y bastante más de la segunda mitad del siglo XX.

Las ilustraciones más extensas y de mejor calidad, realizadas con pintura al agua, suelen encontrarse en cartas de pergamino de gran tamaño de los siglos XVII y XIX. La gran diversidad en tamaños, elementos y pericia de ejecución y el hecho de que algunas monjas tuvieran dos cartas de profesión permiten suponer que su elaboración fue una empresa personal y no pagada por el convento por lo que algunas se tuvieron que conformar con un simple texto escrito, otras se las ilustraron ellas mismas, las más débiles en cuanto a la iluminación, y, por fin, otras volcaron sus propios recursos económicos en ellas contratando para tal fin a un profesional, un escribano-iluminador. Se ha dicho que las más elaboradas son las de las monjas de coro y velo negro mientras que las de las legas serían más sencillas como corresponde a su distinta consideración socio-económica. Refuerza esta idea el hecho de que las cartas de sor Natividad del Purísimo Corazón (Morán Martí, 25II-1904), sor Encarnación de San Plácido (de Castro Asturias, 4-III-1916) y sor María Concepción de Santa Humbelina (Caballo Pérez, 20-VIII-1916), las tres legas, sean aprovechadas de momentos anteriores con lo que el gasto que se realizó fue mínimo.

Cartas de profesión hechas por grandes maestros de la iluminación debieron tener las hijas de artistas sobresalientes que fue relativamente frecuente que profesaran en los monasterios. Quizás la relación laboral entre los artistas, escultores, pintores, orfebres..., y el convento hizo que éstos miraran con interés la posibilidad de situar a algunas mujeres de su familia en ese entorno. Muy conocido es el caso de tres hijas de Pedro de Mena que profesaron en el monasterio de Santa Ana de Málaga: sor Andrea María de la Encarnación y sor Claudia Juana de la Asunción a las que se une posteriormente su hermana Juana Teresa ${ }^{36}$. De las dos primeras se conocen sus magníficas cartas de profesión ${ }^{37}$.

\footnotetext{
${ }^{34}$ AMSC. Vida conventual, Leg. 86, nº 12, p. 322.

${ }^{35}$ AMSC. Vida conventual, Leg. 86, $\mathrm{n}^{\circ}$ 12, p. 164.

${ }^{36}$ GIL MEDINA, Lázaro: Pedro de Mena: Escultor 1628-1688. Madrid, 2007, pp. 49-51.

37 CAMACHO MARTÍNEZ, Rosario: Las cartas de profesión de las hijas de Pedro de Mena. Málaga, 1988.
} 
En San Clemente profesó María de Valdés, hija del gran pintor Juan de Valdés Leal. La trayectoria de María en el monasterio está íntimamente relacionada con la artística de su padre. Éste en 1680, dio carta de pago por los trabajos de dorado y pintura del retablo mayor del monasterio ${ }^{38}$ y poco después, el 20 de abril de 1681, ella tomó el hábito ${ }^{39}$. El padre, coincidiendo con la profesión de su hija $(18-\mathrm{V}-1682)^{40}$, contrató las pinturas de muros y bóvedas del convento que habrían de servir como pago de la dote de María. Como la empresa se prolongara mucho, por otros trabajos del maestro y por su mala salud, Lucas Valdés se comprometió en 1689 a terminarla ${ }^{41}$ haciéndose cargo de esta forma del cumplimiento de la dote de su hermana. Otros miembros de su familia estuvieron también relacionados con el mundo artístico: su madre Isabel de Carrasquilla, su hermana Luisa Rafaela y ella misma de la que se dice que "pintó muy bien al óleo y de miniatura $e$ hizo retratos con facilidad y semejanza"42. Aunque cuando tomó el hábito tenía solo 16 años, debía estar suficientemente preparada a base de participar en el taller familiar como para seguir practicando sus habilidades artísticas dentro de los muros del monasterio y probablemente uno de sus trabajos fuera su propia carta de profesión dado que era iluminadora. Pero no parece corroborar la fama que le atribuye Ceán Bermúdez el que en 1723 fuera designada enfermera ${ }^{43}$, ya con 56 años, y que, por tanto, este encargo le restara tiempo para sus ocupaciones artísticas. A ella misma se le atribuye un cuadro existente allí de santa Gertrudis en la que aparece de medio cuerpo, de frente, sujetando el báculo con la mano derecha mientras se lleva la izquierda al corazón donde está un Niño Jesús. Si exceptuamos la aureola de nueve querubines que rodean a la santa, el cuadro está reproducido en un grabado firmado por Muntaner en el folio de guarda delantero del rico librito de la biblioteca del monasterio, sin catalogar, Novena a la gloriosa virgen Santa Gertrudis la Magna según se practica en el real monasterio de San Clemente de Sevilla compuesta por el P.D.F.X.Q.P.D. O. ${ }^{44}$. El cuadro atribuido a María de Valdés y el grabado de Muntaner fueron modelos para bastantes cartas de profesión.

Pero no solo las profesas ligadas familiarmente a ambientes artísticos debieron tener cartas que fueron verdaderos documentos iluminados en línea con los que se realizaron entre los siglos XVII y XX. Hubo casos en el monasterio de San Clemente en el que cuesta creer que la carta de profesión no hubiera sido hecha

\footnotetext{
38 VALDIVIESO GONZÁLEZ, Enrique: Valdés Leal. Sevilla 1988, p. 33.

39 AMSC. Vida conventual, Leg. 85, nº 18, f. 142 v.

${ }^{40}$ AMSC. Vida conventual, Leg. 85, $\mathrm{n}^{\circ} 18$, f. $152 \mathrm{v}$.

${ }^{41}$ VALDIVIESO GONZÁLEZ, Enrique: Op. Cit., pp. 199-200.

${ }^{42}$ CEÁN BERMÚDEZ, Juan Agustín: Diccionario histórico de los más ilustres profesores de las Bellas Artes en España. Madrid, 1800. T. V, p. 107.

${ }^{43}$ AMSC. Vida conventual, Leg. 85, $\mathrm{n}^{\circ}$ 12, p. 317.

${ }^{44}$ Sevilla: imprenta de la calle de la Mar. Año de 1814.
} 
por un experto escribano-iluminador pues, aunque generalmente anónimas, la habilidad, la técnica, los temas y los recursos estéticos nos inducen a pensar en ello. Este pudo ser el caso de la carta de María Pardo de Cela, hija del hidalgo Arias Pardo de Cela, que tomó el hábito el 17-VI-1624 y profesó el 17-VII-1625⒌ $\mathrm{Su}$ padre tiene una magnífica carta de hidalguía iluminada por el pintor sevillano Diego Gómez ${ }^{46}$ e igualmente la de María pudo haberse encargado a uno de esos pintores que cultivaban también la miniatura o a cualquiera de los talleres de iluminación que por entonces había en Sevilla.

Las cartas de profesión, en general, reflejan la estética del momento al que pertenecen pues el contacto con el mundo artístico fue constante a través de los artistas de todo tipo que trabajan en el convento, de las mismas cartas u otros documentos iluminados procedentes de talleres externos, de las estampas o grabados de algunos libros. En parte estas cartas se asemejan a las de otros conventos, especialmente si son de la misma orden. En el caso del cister femenino los elementos representativos de la orden, san Benito y san Bernardo, las cruces de Calatrava y Alcántara, se repiten necesariamente así como los anagramas de Jesús y María, entre otros temas informativos. Muy interesante sería la comparación entre las cartas, especialmente su decoración, de las monjas cistercienes de distintos cenobios pero eso sería un trabajo muy extenso que escapa a la brevedad de este artículo pues habría que analizar estudios ya realizados ${ }^{47}$ incorporando otros futuros que completarían la visión de conjunto. Fuente de inspiración para las cartas pudo ser el breve del papa Pío VI, de 1783, enmarcado en la sacristía, concediendo indulgencia plenaria a todos los fieles que visitasen la iglesia del monasterio el día del aniversario de las religiosas difuntas. La iluminación, que rodea el texto, está formada por un marco que simula ser de mármol jaspeado, el ancla, que alude a san Clemente, arriba, flores, cintas y elementos vegetales ocres. Otra bula de Pío VIII, expedida en Roma en 1830, declarando y confirmando el título de doctor a san Bernardo, lleva una orla rodeando el texto formada por hojas verdes con abundantes flores multicolores. En la parte superior se encuentra el escudo coronado con la mano de san Bernardo sosteniendo el báculo, además de cruces y la flor de lis.

Pero seguramente fue un motivo de inspiración mucho más importante, por su mayor extensión y abundancia de motivos el Protocolo de las rentas y posesiones

${ }^{45}$ AMSC. Vida conventual, Leg. 85, $\mathrm{n}^{\mathrm{o}} 15$, s/f.

${ }^{46}$ HIDALGO OGÁYAR, Juana: "Diego Gómez, pintor-iluminador del siglo XVII" en Velázquez y su tiempo. Madrid, 1991, pp. 239-246.

${ }^{47}$ GONZÁLEZ DE LA PEÑA, María del Val: Mujer y cultura gráfica: Las Reverendas Madres Bernardas de Alcalá de Henares (Siglos XVIII-XIX). Alcalá de Henares, 2001. CAMACHO MARTÍNEZ, Rosario: "Las cartas de profesión del convento del cister de Málaga...”, op. cit. MARCHANT RIVERA, Ana: Religiosas del Cister malagueño..., op. cit. 
de este real monasterio de San Clemente $^{48}$, finalizado en el mes de diciembre de 1740. El tomo I tiene una iluminación en el folio 1 vuelto, la más reproducida de todas las existentes en el cenobio, que representa a san Fernando glorificado ante un paisaje de Sevilla. Todos los elementos de la orla que lo envuelve, están en línea con las características de la miniatura del siglo XVIII, especialmente con las de las ejecutorias de hidalguía y los privilegios pues es uno más de ellos. El tomo II, en el folio 1 vuelto, tiene una miniatura de san Clemente entronizado con la corona papal y el ancla.

En el monasterio de San Clemente no se conservan cartas de profesión de los siglos XVII y XVIII pues, salvo un par de excepciones, todas son de los siguientes: 33 del XIX, 50 del XX y 28 del XXI ${ }^{49}$. Difícil es explicar la ausencia de estos documentos anteriores al siglo XIX. El convento, pese a la protección real, la alcurnia de sus monjas y sus muchas posesiones, debió pasar con alguna frecuencia por dificultades económicas como demuestra la encuesta realizada en 1531 por el mismo convento para probar la mala situación por la que atravesaban ${ }^{50}$. Desde el siglo XIII y aunque los reyes encargasen del cuidado del monasterio a la Real Cámara de Castilla, no se pudo conseguir, por descuido de sus mayordomos, que se hiciera efectivo el reconocimiento de sus posesiones hasta la cédula de Felipe V, dada en San Ildefonso el 9 de octubre de 1732, y otra posterior, dada en E1 Pardo el 26 de febrero de $1737^{51}$. Esta precariedad económica podría quizás justificar la inexistencia de cartas anteriores a este momento.

Las riadas y sus consecuencias pudieron ser una de las causas que acabaron casi totalmente con las cartas de los siglos XVII y XVIII. Dos de las peores fueron las de 1626 y 1642 y muy grandes también las de 1684, 1691, 1692 y 1697. Cualquiera de estas cuatro últimas pudo haber mojado las cartas del siglo XVII aunque no se puede descartar que fuera en riadas posteriores pues Sevilla siguió sufriendo esta lacra hasta el siglo XX. Una vez humedecidas o definitivamente arruinadas las cartas, quizás fueron aprovechadas como material de segunda para otros fines como, por ejemplo, para encuadernar, ya que serían de pergamino. Este ha sido el caso de la única localizada del siglo XVII en el monasterio de San Clemente que hasta este momento acogió, doblada por la mitad, a manera de forro o tapadera, una serie de partituras. En una de las tapas, por el revés de la carta original, dice Canto llano y en la otra Introitos, Himnos... Sobre el derecho de la carta una inscripción deja constancia de cuando fue aprovechada: Año de 1712... fesit con lo que el "arreglista" dejó muestras de su seseo. La carta, de pergamino, tiene unas dimensiones de 307 x $440 \mathrm{~mm}$. y sobre ella pegado un papel que de

${ }^{48}$ AMSC. Secc. Protocolos. Libro de Protocolo de las rentas y posesiones de este real monasterio de San Clemente. T. I ( $\mathrm{n}^{\circ} 1$ al 237) y T. II ( $\mathrm{n}^{\circ} 238$ al 498).

49 AMSC. Vida conventual, cajón séptimo del planero del archivo.

${ }^{50}$ AMSC. Vida conventual, Legajo 85, $\mathrm{n}^{\circ} 6$.

51 AMSC. Secc. Protocolos, Protocolo de las Rentas y Posesiones... T. I, f. 7 recto. 
retirarse se llevaría texto y decoración pero que al trasluz no dificulta demasiado su visión. La propietaria es Fabiana Eugenia Arias Maldonado, de 25 años más o menos, natural de Sevilla, hija del capitán Diego Arias Maldonado y de su mujer Beatriz María de Lemos que tomó el hábito el 20 de abril de 1662 y profesó el 25 de mayo de 1663 , fecha de la carta $^{52}$. Una orla multicolor vegetal rodea el documento acogiendo en la parte superior el nombre de la profesa. La E(go), metida en un rectángulo de gran tamaño, responde por sus elementos, roleos que se enroscan, hojas que se vuelven, y colores, al modelo más usado en la miniatura del siglo XVII (Figura 3). Tres carteles con las mismas características descritas acogen las firmas la de la madre abadesa, Leonor de Oliva y Vargas, a la izquierda, la de la autoridad eclesiástica que ha realizado la ceremonia, el visitador de la orden, en el centro y la de la profesa a la derecha. La carta fue, antes de su deterioro un documento muy bien iluminado y plenamente encajado en el siglo XVII por su colorido, sus elementos vegetales, con sus características hojas curvadas, y el tamaño y distribución de su decoración.

El único rastro que se conserva de las cartas del siglo XVIII es un papel manuscrito referido a sor Francisca del Espíritu Santo (13-VI-1791), en el siglo Francisca Antonia de la Maza Magallanes, que tomó el hábito el 1 de marzo de 1790 con 19 años, profesó el 12 de junio de $1791^{53}$, en 1801 estuvo al cuidado el aniversario de las ánimas ${ }^{54}$, en 1813 fue enfermera y posteriormente elegida para el Prefectorio ${ }^{55}$.

Lo peor que les ha pasado a las cartas de profesión, especialmente del siglo XIX, es su transformación pues algunas nuevas profesas se apropiaron de documentos anteriores. Es de suponer que elegirían las más vistosas, las mejor conservadas y las que por su iconografía respondieran mejor a su nombre, al de sus padres o a sus devociones particulares. Para aprovechar las cartas de profesión anteriores y adaptarlas a su nueva propietaria se borró el texto o se pegó un papel sobre él en donde se recogían los nuevos datos, se borró a veces la iluminación y se hicieron diversos ensayos de aprovechamiento que en ocasiones terminaron arruinando los documentos originales.

Una carta de profesión aprovechada, de pergamino, cuyo texto ha sido borrado sin dañar la decoración, es la de sor Natividad del Purísimo Corazón de la Beatísima Virgen María (25-II-1904), en el siglo Natividad Morán Martí, que tomó el hábito el 19 de febrero de 1903 e hizo la profesión simple el 24 de febrero de 1904. Hizo los votos solemnes el 29 de abril de 1907 y fue redimida del cargo de cantora por una dote perpetua que dejó Ángela Caro para que rezara parte del

${ }^{52}$ AMSC. Vida conventual, Leg. 85, no 18 , ff. 4 v. y $10 \mathrm{v}$.

53 AMSC. Vida conventual, Libro de Ábitos... de 1788, ff. 4 v. y 5 r.

${ }^{54}$ AMSC. Vida conventual, Leg. 86, $\mathrm{n}^{\mathrm{o}}$ 45, s/f.

${ }_{55}$ AMSC. Vida conventual, Leg. 85, n 12, pp. 321 y 329. 
rosario por ella ${ }^{56}$. Bajo el texto habitual se encuentran las firmas de la abadesa sor Flora Salgado, el oficiante Fernando Cermeño, de la Compañía de Jesús, y sor Natividad. El óvalo que acoge el texto está íntegramente envuelto por una decoración vegetal, guirnaldas, palmas, hojas verdes y una gran variedad de pequeñas flores multicolores entre las que se alojan arriba el corazón radiante de María, que alude al nombre de la monja, con las cruces de Calatrava y Alcántara a derecha e izquierda; a un lado y otro la corona papal y el ancla refiriéndose a san Clemente y debajo el escudo real significando la protección del monarca. Completan la decoración simbólica los anagramas de Cristo y María. El borrado del texto original es tan eficiente que no permite entrever ningún dato de la carta original pero su decoración está relacionada con la del manuscrito de la Misa de San Benito $\mathrm{Abad}^{57}$ que fue escrita por Josefa de Quesada en 1851 que, con toda probabilidad, realizó las dos orlas que envuelven los grabados coloreados de San Benito y San Bernardo compuestas por las mismas guirnaldas con flores salteadas, las mismas hojas verdes y las mismas palmas que la carta de profesión. Así pues, la fecha del documento original debe estar en la medianía del siglo XIX.

Igualmente borrada de forma impecable aunque el aprovechamiento se aprecia en los borrones que han dejado las firmas primitivas, es la carta de sor Josefa de Jesús y María (29-XI-1906), en el siglo Josefa Díaz Gelo, que toma el hábito el 1905 y profesa al año siguiente. Es de cartón y lleva las firmas del oficiante, Bartolomé Romero Gago, de la abadesa, Fermina Fernández Alfonso, y de la profesa. Variados elementos vegetales multicolores envuelven el texto, cuatro cruces de distinto tipo, Calatrava, Alcántara, Santiago y latina, los corazones de Jesús y María y los anagramas de ambos. Prácticamente idéntica es la carta original de sor María Dolores del Amor de Dios (29-I-1891) que, aunque ha sufrido otro tipo de alteración, nos sirve para fechar la aprovechada en quince años atrás.

Otra carta de profesión aprovechada por el sistema de borrar el texto de la original, es la de sor María Concepción de Santa Humbelina (20-VIII-1916), en el siglo Concepción Caballo Pérez, que tomó el hábito el 2 de agosto de 1915 y profesó un año después. El texto se inscribe en un óvalo central bajo el cual se encuentran las tres firmas: de la abadesa, Josefa Benítez, del oficiante, Luciano Rivas, y de la profesa. Esta última denota torpeza, poca práctica a la hora de escribir, como corresponde a su condición de lega. La ilustración responde a elementos representativos del monasterio. Es evidente el parecido de esta carta con la original de sor María de San Luis Gonzaga (1-X-1818), en el siglo María de la Salud Ruibal Pozo que tomó el hábito el 8 de septiembre de 1817 y profesó un año después. En la parte inferior, debajo del texto, distintos elementos dibujan dos rombos y una cartela que acogen las firmas de la abadesa, Nicolasa Caballero, de Vicente Seise, que firma por comisión del visitador, y de la profesa (Figura 4). Las

\footnotetext{
56 AMSC. Vida conventual, Libro de Ábitos... de 1788, pp.295, 296 y 298.

57 Biblioteca del monasterio de San Clemente, sin catalogar.
} 
dos están encajadas en el mismo marco cuyos ángulos ocupan rosas y hojas verdes; las dos encierran el texto en un óvalo que en la parte superior lleva una guirnalda de flores y hojas, en el centro de la cual se encuentra el escudo real con dos palmas; las dos llevan como soporte de ese óvalo una flor, unas palmas que terminan acogiendo los espacios para las firmas, las dos son de cartón. Parece razonable pensar que la fecha de la carta original que aprovechó sor María Concepción de Santa Humbelina se encuentra a principios del siglo XIX.

Una fórmula distinta para reutilizar una carta antigua es pegar sobre ella un papel donde escribir los nuevos datos. Así se ha hecho en la carta de sor Manuela de San Luis Gonzaga (17-XI-1907), en el siglo Manuela Vizcaino Palanco, que tomó el hábito el 11 de noviembre de 1907 profesando un año después. Sobre la carta original de pergamino se han pegado cuatro óvalos de papel el mayor de los cuales contiene la fórmula habitual de profesión y los otros tres acogen las firmas de la abadesa, Fermina Fernández, del oficiante, Enmanuel María Baena Marín y de la profesa. La delicada decoración de este documento no contiene ningún elemento que haga referencia concreta al monasterio de San Clemente. En la parte superior aparece el triángulo radiante, representativo de la Trinidad, bajo él una cruz atravesando una corona de rosas blancas y, enmarcando el texto una rama de azucenas y otra de rosas (Figura 5).

En el caso de la carta de sor María Encarnación de San Plácido (21-III-1917), en el siglo Encarnación de Castro Asturias, que tomó el hábito el 4 de marzo de $1916^{58}$ e hizo los votos simples un año después, el sistema para aprovecharla ha sido el mismo, pegar sobre el texto unos papeles que contienen los nuevos datos, entre ellos las firmas de la abadesa, sor Josefa Benítez y del oficiante, Luciano Rivas Santiago, deán de la catedral y visitador general. Del óvalo que debía contener la firma de la profesa, que era lega, se ha despegado el papel dejando leer la de la anterior propietaria. Se trata de Consolación Velázquez Gaztelu Ponce de León que entró en el monasterio de educanda con 12 años, tomó el hábito el 25 de abril de 1878 con 29 , profesó el 26 de mayo de 1879 , fue superiora y murió el 24 de septiembre de 1903. Solo 13 años después de su muerte fue despojada de su propiedad. La razón por la que sor María Encarnación se apoderó de esta carta, aparte de porque es de pergamino y su iluminación es notable, es porque en la ilustración superior se representa el momento de la Encarnación. Bajo él aparece una monja arrodillada dándole la mano a Jesús Resucitado. Alrededor del texto, metidos en clípeos enlazados por finos elementos vegetales, diez santos: representativos de la orden, del monasterio, del nombre de la monja y de sus familiares o de sus devociones particulares. Soportando el texto un jarrón con flores flanqueado por dos bellos ángeles. Los ángeles tienen la parte inferior del cuerpo formado por unas hojas abrochadas que se están usando en miniatura

\footnotetext{
${ }^{58}$ AMSC. Vida conventual, Libro de Ábitos... de 1788, p. 324.
} 
desde el siglo XVII (Figura 6). La carta es una completa declaración de intenciones pues acumula todo el simbolismo y las leyendas alusivas a la propietaria original de ella.

Un papel pegado encima de la carta original tuvo también la de sor María Catalina de Monte Carmelo (6-V-1883), en el siglo Catalina Calero Parreño, que tomó el hábito el 30 de abril de 1882 y profesó al año siguiente ${ }^{59}$ siendo el oficiante el obispo Marcelo Spínola y Maestre, visitador de la orden, y la abadesa María del Patrocinio Caro. Las firmas están borradas y en su lugar aparecen otras posteriores: la del oficiante, José María Rodríguez, la de la abadesa Fermina Fernández Alfonso y la de Concepción Bulnes Cantorera que tomó el hábito el 18 de octubre de 1896, con 29 años, y profesó el 27 de octubre del año siguiente. Es decir, se apropió de la carta de profesión original solo 14 años después de realizada. El documento responde a un modelo repetido en los años finales del siglo XIX y luego imitado en las medianías del XX. Una serie de elementos geométricos y vegetales enmarcan el texto y los tres espacios que han sido reservados originalmente para las firmas que han sido borradas. En la parte superior el anagrama de María y bajo él el de Cristo, alrededor de la carta cuatro escudos conteniendo las cruces habituales. Completan la escueta decoración unas pocas flores. El mismo esquema repiten las cartas de sor Celedonia María de los Dolores y de San Ignacio (21-XII-1896) y de sor Josefa de San Vicente (21-XII-1896. Las tres cartas son del mismo material, papel, y de medidas muy semejantes ${ }^{60}$.

Muy ilustrativo del sistema de pegar un papel encima de una carta para aprovecharla es la de sor María Patrocinio de Santa Gertrudis (31-XII-1854) pues existe una fotografía de cuando este papel, que además se conserva, estaba todavía allí. María del Amparo Caro Ganzinotto tomó el hábito el 8 de noviembre de 1853, profesó, cambiando de nombre, el 30 de diciembre de $1854^{61}$, fue elegida superiora el 17 de abril de 1871 y abadesa el 22 de diciembre de $1880^{62}$ muriendo el 4 de agosto de 1894. El texto, encajado dentro de un paño colgante, ha sido parcialmente borrado así como las firmas originales. Ha tenido pegada encima la carta, solo escrita, de sor María del Carmen de Santa Catalina (7-V-1908), en el siglo Carmen Pagador Ortiz, que tomó el hábito el 5 de mayo de 1907 con 19 años y profesó el 10 de mayo de $1908^{63}$. Solo 14 años después de la muerte de la propietaria primitiva se la despoja de su carta. Las firmas del oficiante, el canónigo Bartolomé Romero Gago, la abadesa, Fermina Fernández y la profesa se conservan en la carta original. Ésta ha sido elegida indudablemente por su calidad, pues es de

\footnotetext{
${ }^{59}$ AMSC. Vida conventual, Libro de Ábitos... de 1788, pp. 251 y 256.

${ }^{60} 650 \times 500 \mathrm{~mm}$.

${ }^{61}$ AMSC. Vida conventual, Libro de Ábitos... de 1788, ff. 181 r. y 185 r.

${ }^{62}$ AMSC. Vida conventual, Leg. 85, no 12, pp. 132 y 134.

${ }^{63}$ AMSC. Vida conventual, Libro de Ábitos... de 1788, pp. 302 y 305.
} 
vitela, su tamaño ${ }^{64}$, y, sobre todo, por su iluminación. Elementos vegetales, florales, roleos y cordadas de perlas enlazan el óvalo superior, que representa la Transfiguración, con los corazones de Jesús y María y con el resto de los elementos. A una y otra parte del texto seis tondos formados por guirnaldas de flores y palmas alojan, entre otros santos, a santa Gertrudis, en clara referencia al nombre de la primitiva propietaria (Figura7). La santa está reproduciendo punto por punto el grabado de Muntaner del libro Novena a Santa Gertrudis que se encuentra en la biblioteca del monasterio (Figura 8).

Menos frecuente es el que para aprovechar una carta anterior se borre parte de la iluminación. Este es el caso de la de sor María Josefa de Santa Gertrudis (12-X-1861), en el siglo María Josefa Barrera Linón, que tomó el hábito el 15 de agosto de 1861 y profesó el 19 de agosto del año siguiente. El óvalo central ha sido borrado y vuelto a pintar con una Virgen Dolorosa inacabada con el color corrido, cuya impericia contrasta con los cuatro clípeos, con toda seguridad originales. El texto aporta aún más confusión para interpretar este documento pues las firmas no existen, la fecha no coincide con la de la profesión, ni los nombres del oficiante, Manuel Joaquín, y de la abadesa, María de la Salud Ruibal Flores, con los de otra carta de la misma monja. Todo parece indicar que el documento se sacrificó en aras de un ensayo que salió mal sin conseguir adaptarla a su nueva propietaria por lo que se tuvo que conformar con una original más sencilla.

Otro tipo de alteración, es el que ha sufrido la carta de sor María Dolores del Amor de Dios ( 29-I-1891), en el siglo Dolores González Gil, que tomó el hábito el 2 de julio de 1889 y profesó al año siguiente ${ }^{65}$. Elementos vegetales delimitan los espacios donde se alojan el texto con las firmas del oficiante, Francisco Bermúdez de Cañas, la abadesa, Fermina Fernández y la profesa, y los temas alusivos. Entre ellos destacan dos miniaturas de cierto mérito de san Clemente y san Fernando y dos círculos limpiamente recortados, semejantes a los anteriores en situación y tamaño que contendrían las miniaturas de san Benito y san Bernardo (Figura 9). Extraídos por los años cincuenta del siglo pasado fue, presumiblemente, la devoción que la orden les tiene lo que generó esta acción.

La reutilización de cartas de profesión anteriores se perpetró fundamentalmente en el siglo XX. Desde 1904 hasta 1917 hay seis cartas aprovechadas de las nueve que corresponden a este periodo. La última iluminada, que es original, es la de sor María Luisa de la Natividad de la Virgen María y del Espíritu Santo (20VII-1941), en el siglo María Luisa Ormas González que tomó el hábito el 16 de julio de 1940 y profesó un año después. El documento vuelve los ojos al siglo XV del que imita los temas: la letra cardinal $\mathrm{E}(\mathrm{go})$ va sobre un fondo dorado con escotaduras y junto a ella aparecen pequeños elementos trilobulados de oro.

\footnotetext{
${ }^{64} 565 \times 420 \mathrm{~mm}$.

${ }^{65}$ AMSC. Vida conventual, Libro de Ábitos... de 1788, p. 283.
} 
De algunas monjas se conservan dos cartas de profesión, caso de sor María Ángela de Jesús y de San Ignacio, en el siglo María Ángela Gómez Marañón, que tomó el hábito el 23 de marzo de 1852 y profesó el 19 de julio del siguiente año ${ }^{66}$. Viuda de su primer marido, se volvió a casar por poderes, matrimonio que no prosperó por lo que, entendiendo que era una señal, tomó el hábito ya con 29 años, viviendo en el monasterio durante 47 más. Murió a los 76 años el 22 de diciembre de 1898 dejando grata y perdurable memoria según reza en su lápida. Una de sus dos cartas de profesión (21-VII-1853), de pergamino, es la mayor de todas las que se conservan ${ }^{67}$. Su excepcionalidad no le viene dada únicamente por el tamaño sino por su iluminación pues ha sido hecha por un miniaturista experto y sigue un programa iconográfico que, presumiblemente, está impuesto por ella misma. El texto está inmerso en un óvalo formado por la corona de espinas entrelazada con hojas azules y rosas de té. Las firmas, del canónigo de la catedral Juan Manzano, de la abadesa, Petra Navarro y de la profesa, se encuentran en un paño bajo él. La parte superior está ocupada por el triángulo con el ojo de Dios dentro que emite unas potentísimas ráfagas e inmediatamente debajo de él la Virgen con el Niño ante los que se arrodilla la monja. Los demás personajes, todos con aureola dorada en los que aparecen sus nombres, aluden a la orden, al monasterio, a su propio nombre, el ángel de la guarda y san Ignacio de Loyola, al de su madre, san José y a sus devociones particulares. Siendo todas las figuras de una gran perfección se llevan la palma por su mayor tamaño dos bellísimos ángeles que sostienen el óvalo con el texto y que, junto a otros ángeles niños, vuelven a hacer referencia al nombre de la profesa (Figura 10). La otra carta de sor María Ángela de Jesús y de San Ignacio es más sencilla.

Fecha de recepción: 15 de septiembre de 2015.

Fecha de aceptación: 20 de noviembre de 2015.

\footnotetext{
${ }^{66}$ AMSC., Vida conventual, Libro de Ábitos... de 1788, folio $174 \mathrm{r}$.

${ }^{67} 650 \times 525 \mathrm{~mm}$.
} 


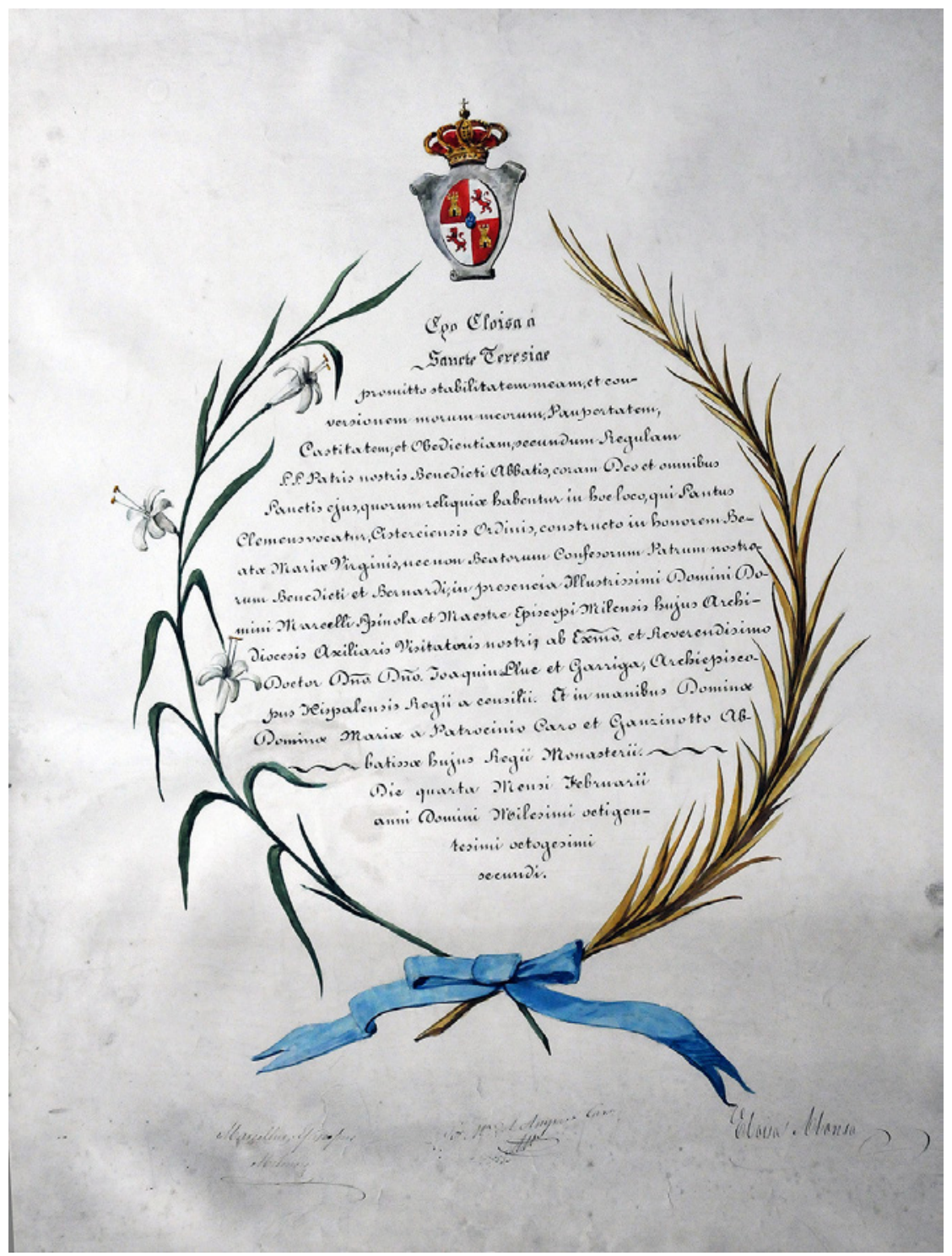

Figura 1. Carta de profesión de sor Eloísa de Santa Teresa, 4-II-1882. 


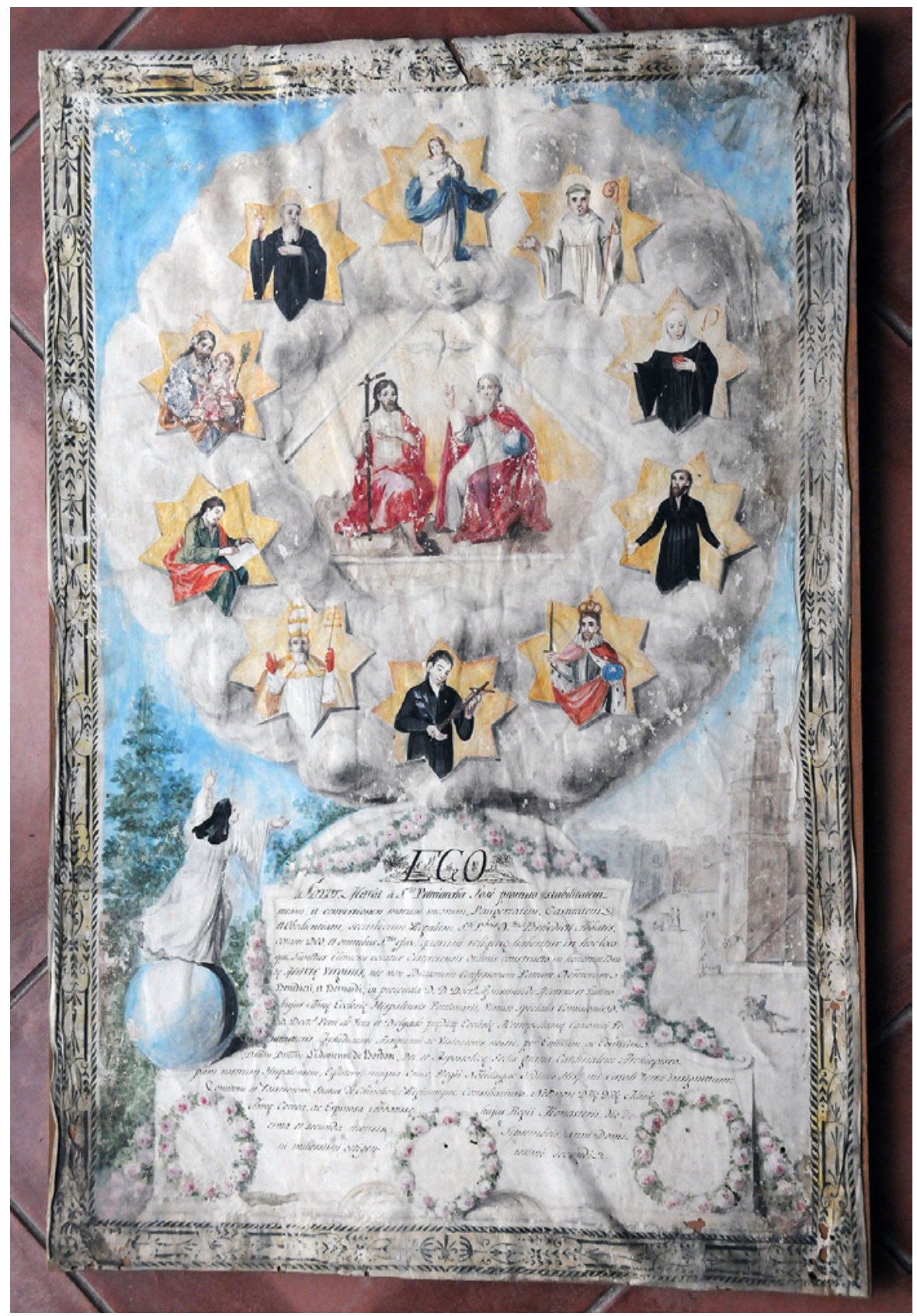

Figura 2. Carta de profesión de sor María del Santo Patriarca José, 12-IX-1802. 


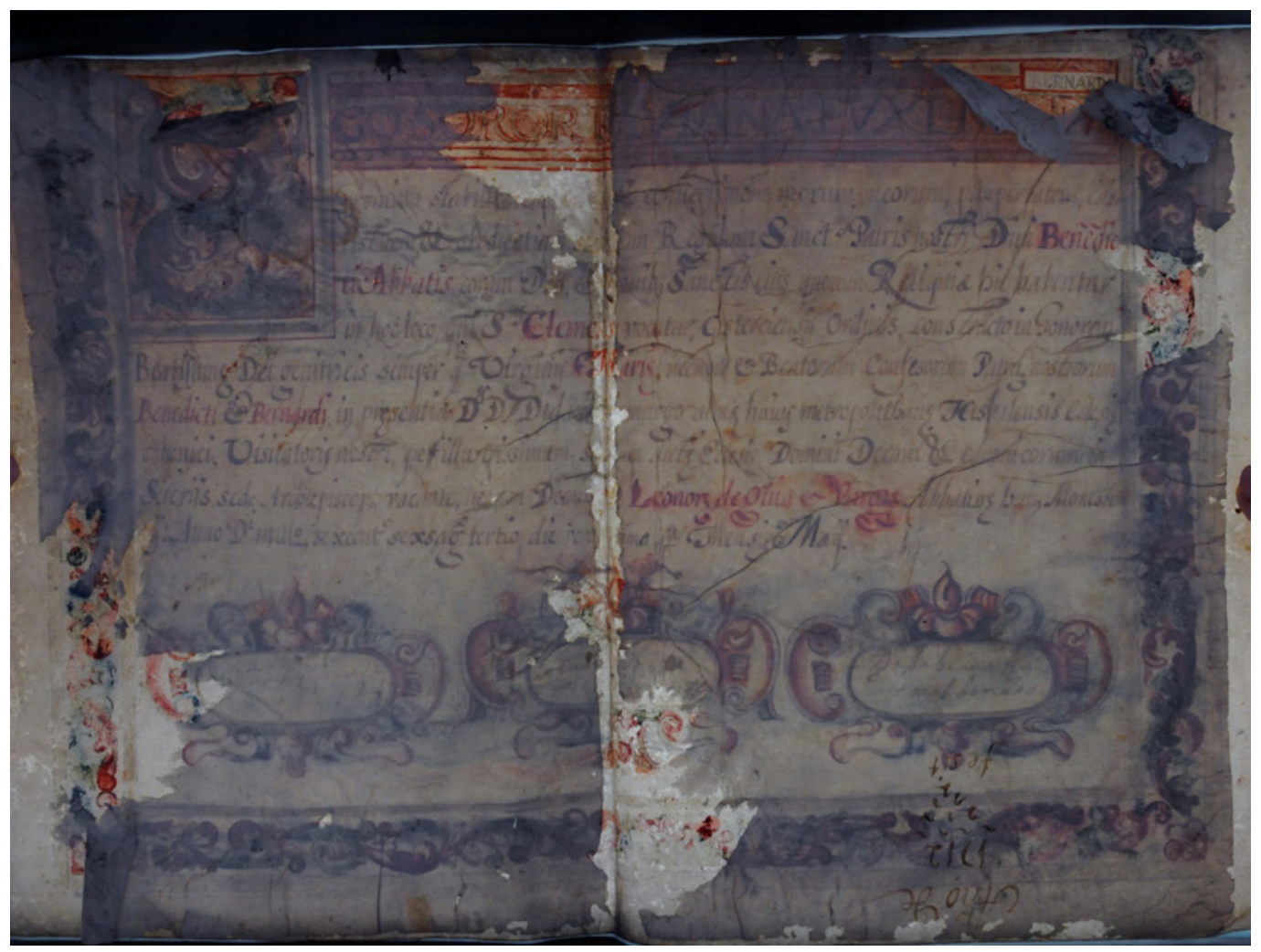

Figura 3. Carta de profesión de sor Fabiana Eugenia Arias Maldonado, 25-V-1663. 


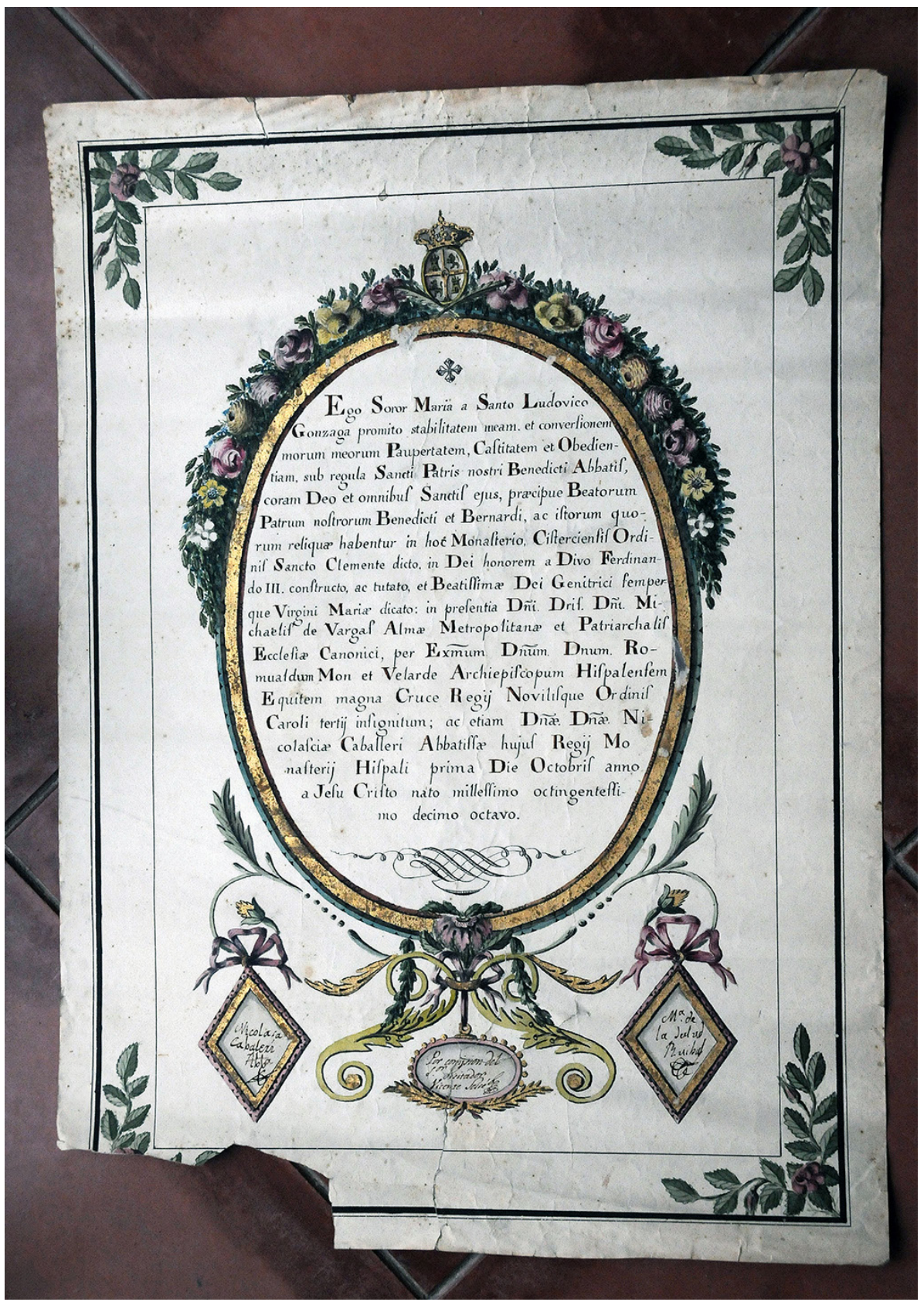

Figura 4. Carta de profesión de sor María de San Luis Gonzaga, 1-X-1818. 


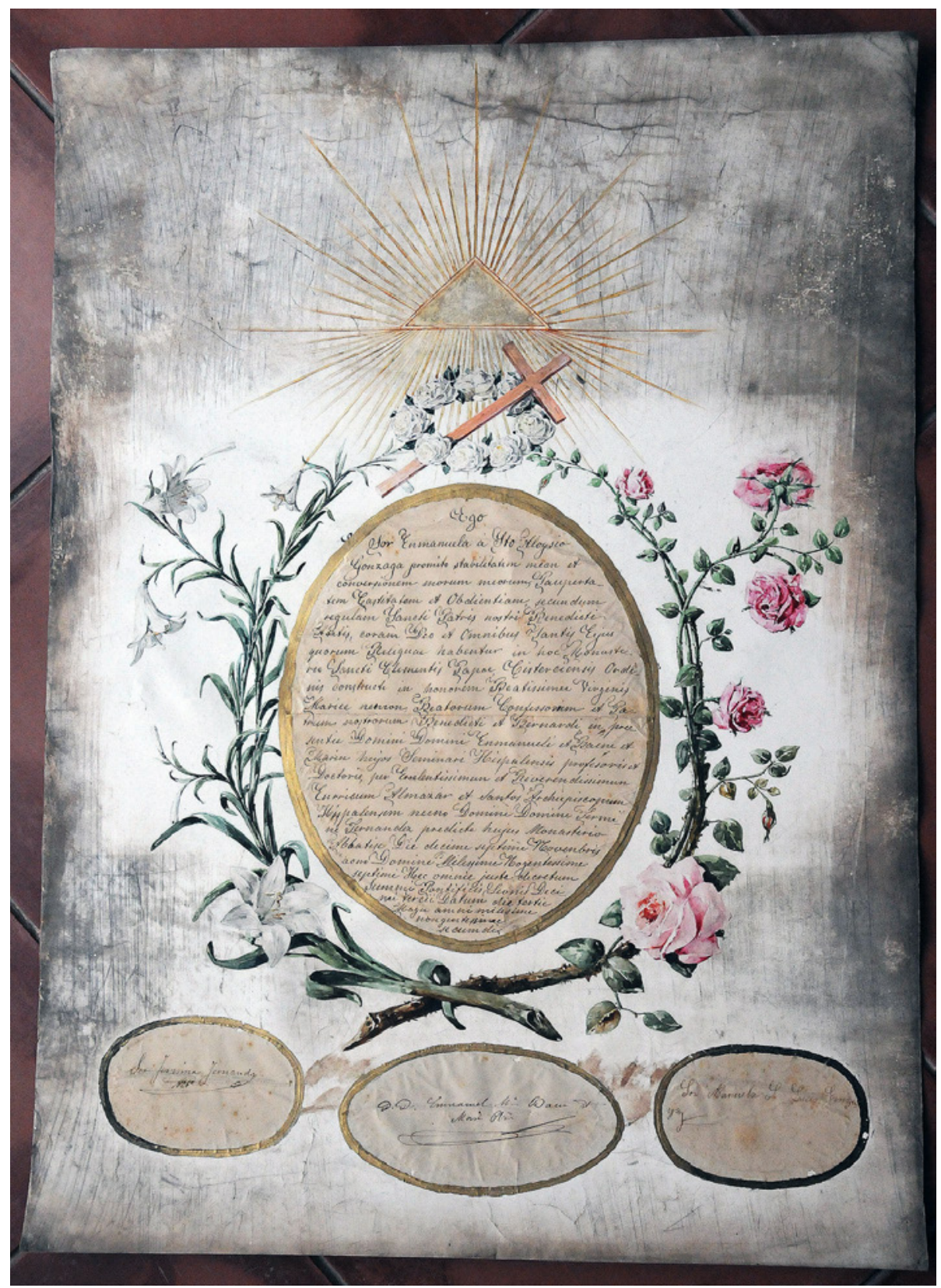

Figura 5. Carta de profesión de sor Manuela de San Luis Gonzaga, 17-XI-1907. 


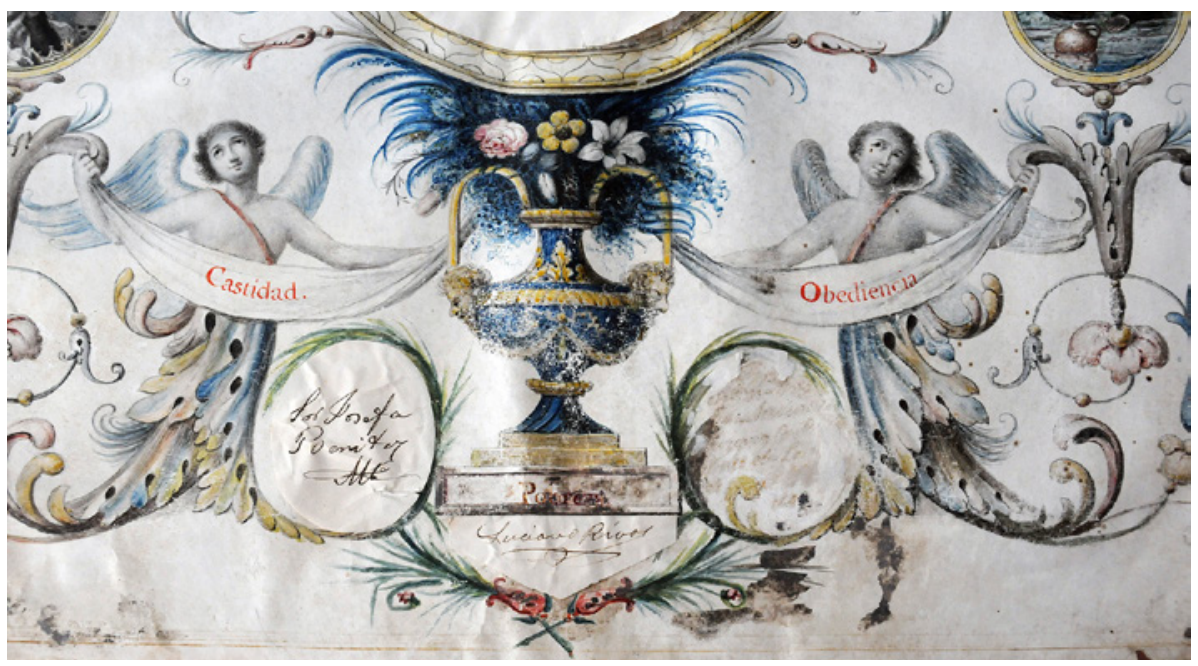

Figura 6. Carta de profesión de sor María Encarnación de San Plácido. 21-III-1917. Detalle.

Figura 7. Carta de profesión de sor María del Patrocinio de Santa Gertrudis, 31-XII-1854.

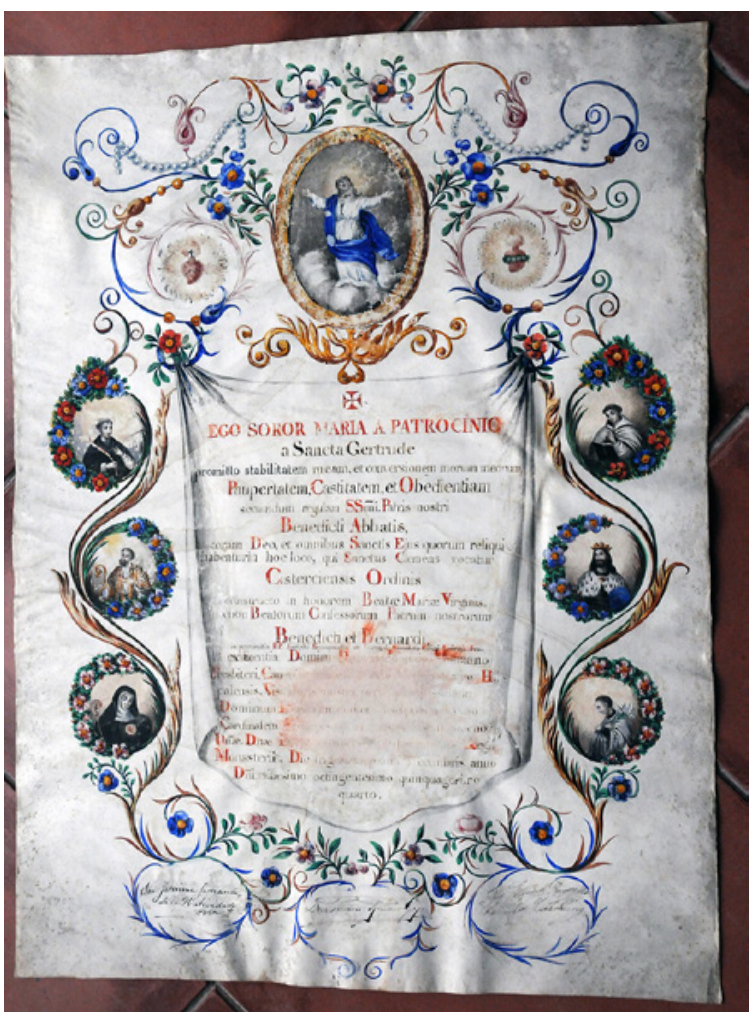




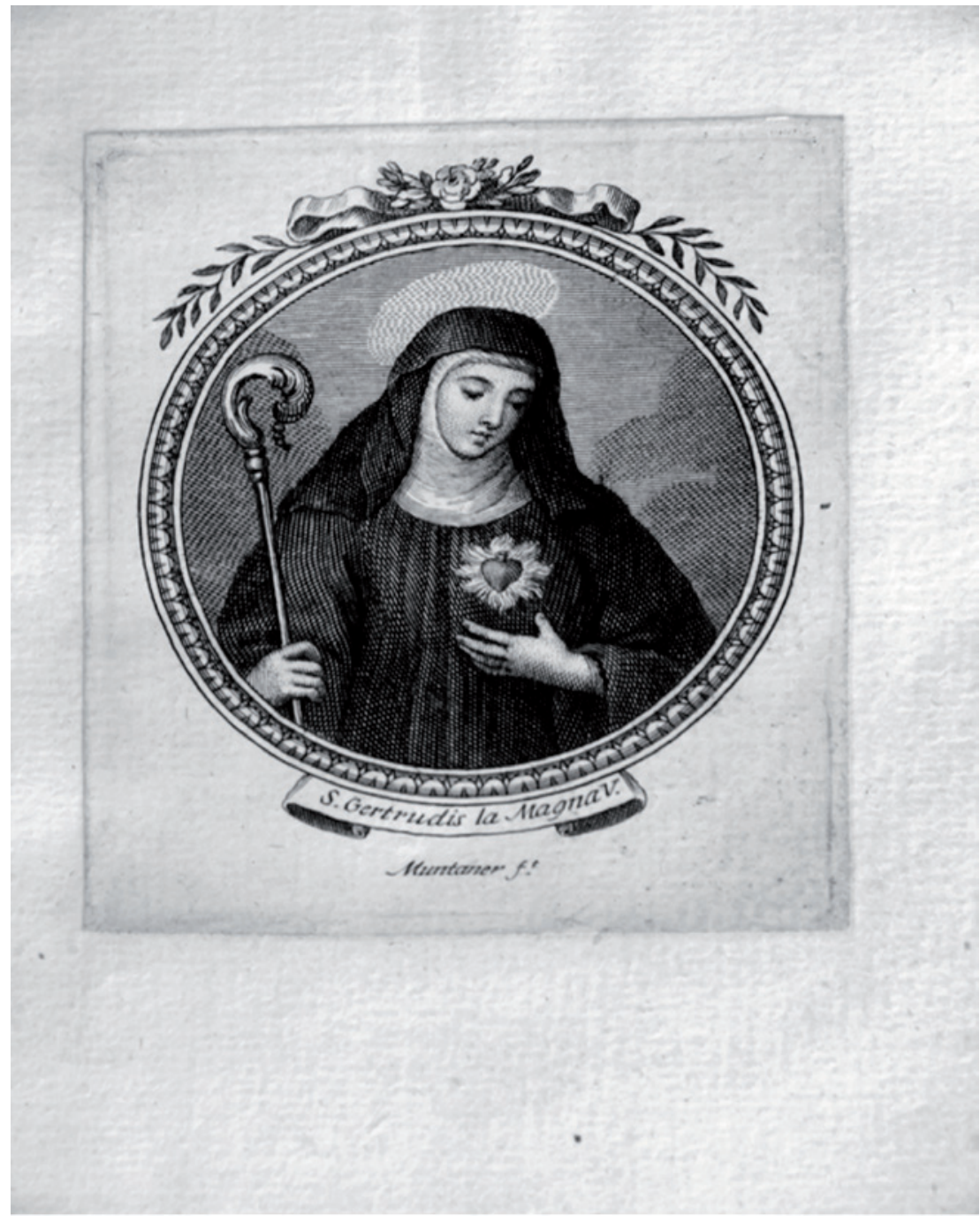

Figura 8. Grabado de Santa Gertrudis del libro Novena a la gloriosa virgen Santa Gertrudis la Magna según se practica en el real monasterio de San Clemente de Sevilla, folio de guarda delantero. 


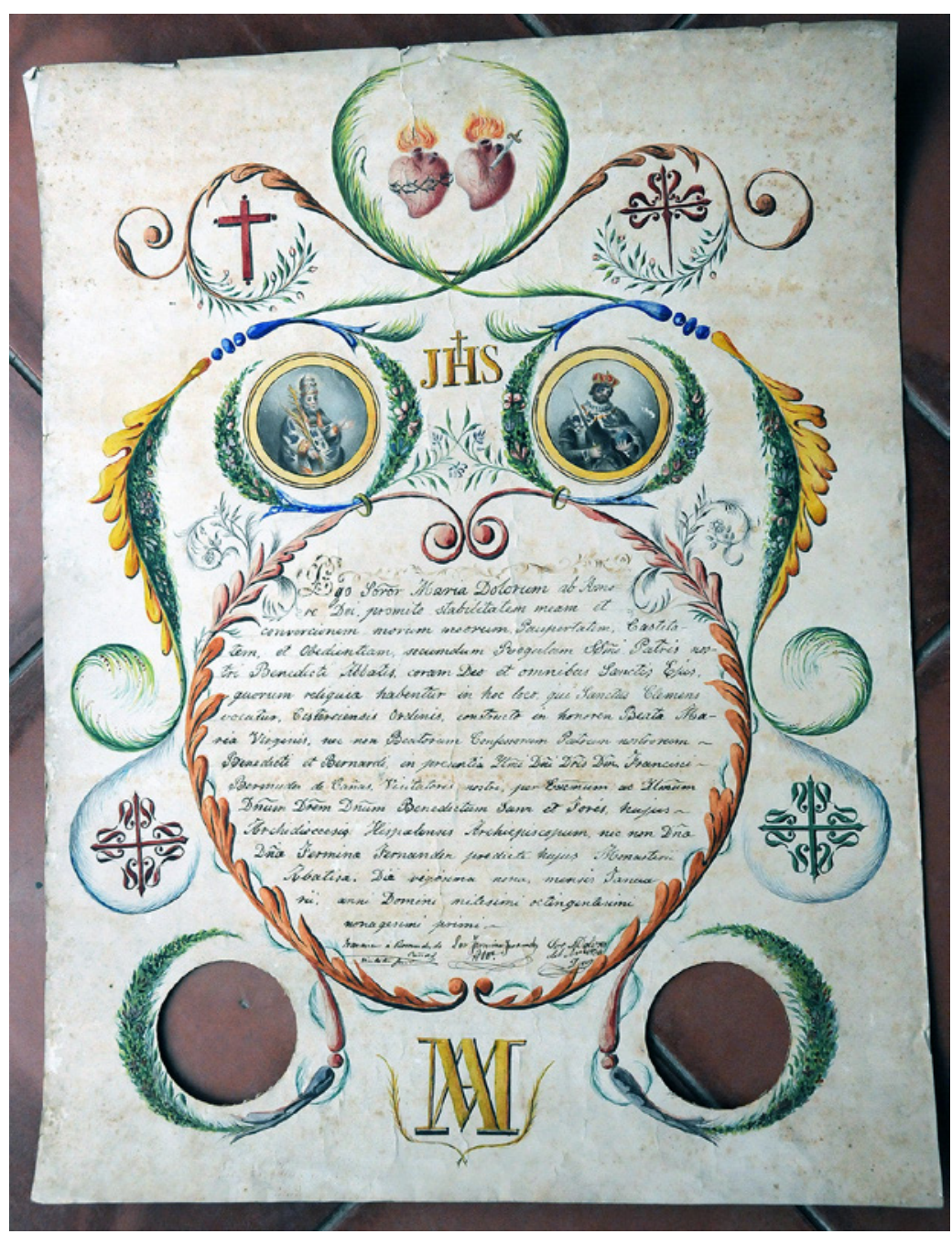

Figura 9. Carta de profesión de sor María Dolores del Amor de Dios, 29-I-1891. 


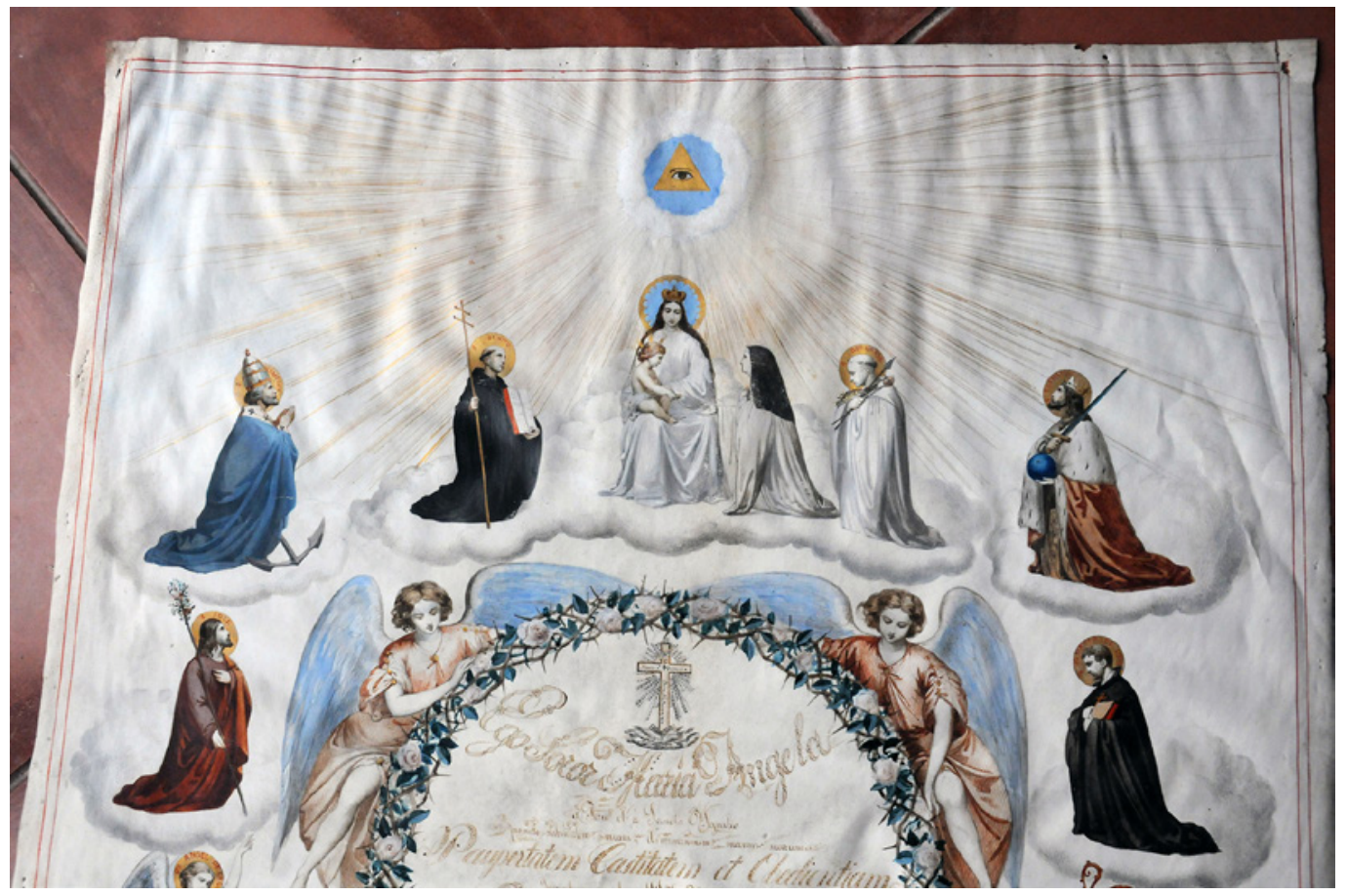

Figura 10. Carta de profesión de sor María Ángela de Jesús y de San Ignacio, 21-VII-1853. Detalle. 